Typeset using jjap.cls <ver.1.0.1 $>$

\title{
Growth and Characterization of SiC Films by Hot-Wire Chemical Vapor Deposition at Low Substrate Temperature Using $\mathrm{SiF}_{4} / \mathrm{CH}_{4} / \mathrm{H}_{2}$ Mixture
}

Takahiro Kida, Yohei Nagas aka, Takuya SAkurai, Tomohiko Yamakami, Rinpei Hayashibe, Katsuya ABE, and Kiichi KamimurA*

Department of Electrical and Electronic Engineering, Faculty of Engineering, Shinshu University, 4-17-1 Wakasato, Nagano 380-8553, Japan

(Received

Microcrystalline SiC films were grown by hot-wire chemical vapor deposition (HWCVD) at a low substrate temperature using a $\mathrm{SiF}_{4} / \mathrm{CH}_{4} / \mathrm{H}_{2}$ mixture, and their structural properties were characterized. Low growth pressure resulted in a narrow full width at half maximum (FWHM) of the Si-C peak in Fourier transform infrared absorption spectroscopy (FT-IR) spectra. The deposition rate and the FWHM value increased with increasing filament temperature. This seemed to be caused by change of the concentration ratio of precursors on the growth surface with increasing filament temperature. Also, the film crystallinity depended on the $\mathrm{CH}_{4} / \mathrm{SiF}_{4}$ flow rate ratio, and $\mu \mathrm{c}-3 \mathrm{C}-\mathrm{SiC}(111)$ films were successfully obtained at low substrate temperature of $250^{\circ} \mathrm{C}$.

KEYWORDS: hot wire, CVD, 3C-SiC, $\mathrm{SiF}_{4}, \mathrm{H}_{2}$ dilution, low-temperature film growth

\footnotetext{
${ }^{*}$ E-mail address: kamimr@shinshu-u.ac.jp
} 


\section{Introduction}

Silicon carbide $(\mathrm{SiC})$ is a promising material for a wide variety of device applications and for replacing conventional semiconductor materials such as silicon and gallium arsenide (GaAs) in certain critical applications. In particular, $\mathrm{SiC}$ has attracted recent attention for use in high-power and high-temperature devices because of its superior properties such as a wide band gap, a high breakdown field, and a high thermal conductivity. ${ }^{1}$ It is widely recognized that high temperatures above $1200^{\circ} \mathrm{C}$ are required for the preparation of crystalline SiC films by thermal chemical vapor deposition (CVD). This high growth temperature prevents flexibility in the design of electronic devices.

Amorphous $\mathrm{SiC}$ and microcrystalline $\mathrm{SiC}$ films can be prepared at substrate temperatures lower than $300^{\circ} \mathrm{C}$ by plasma-enhanced (PE) CVD and hot-wire (HW) CVD. Recently the low-temperature epitaxial growth of $3 \mathrm{C}-\mathrm{SiC}$ has also been reported. ${ }^{2)}$ In the $\mathrm{SiC}$ growth by PECVD, various $\mathrm{Si}$ sources, such as $\mathrm{SiH}_{4},{ }^{3)}$ methylsilanes, ${ }^{4)}$ and silicon halide, ${ }^{5)}$ have been used. $\mathrm{SiH}_{4}$ and methylsilane have also been applied to HW-CVD. ${ }^{6,7}$ ) Here, atomic hydrogen plays a key role.

It is expected that fluorosilane gases can be used in Si film growth for the removal of the surface oxide from the substrate without cleaning procedures because of their etching capability ${ }^{8)}$ which is advantageous for producing $\mathrm{SiC}$ films with favorable crystallinity ${ }^{9,10)}$ and electrical properties. $\left.{ }^{11}\right)$ Silicon tetrafluoride $\left(\mathrm{SiF}_{4}\right)$ has been used as a Si source for preparing $\mathrm{SiC}$ film by plasma CVD. ${ }^{12)}$ However, SiC film growth by HW-CVD using silicon halide sources has not been reported.

In this study, microcrystalline SiC films were grown by HW-CVD at a low substrate temperature using a $\mathrm{SiF}_{4} / \mathrm{CH}_{4} / \mathrm{H}_{2}$ mixture, and their structural properties were characterized.

\section{Experimental Procedure}

The SiC films were grown on $\mathrm{Si}(001)$ and $\mathrm{Si}(111)$ substrates using a HW-CVD system with an "S"-shaped tungsten filament as a hot wire. The filament diameter and length were 0.5 and $150 \mathrm{~mm}$, respectively. The filament-substrate distance was maintained at $40 \mathrm{~mm}$. The growth chamber was evacuated to $2 \times 10^{-6}$ Torr using a turbo-molecular 
pump. The source gases were $\mathrm{SiF}_{4}(>99.999 \%)$ and $\mathrm{CH}_{4}(>99.999 \%) . \mathrm{H}_{2}(>99.99999 \%)$ was used as a dilution gas. The substrates were cleaned by an ultrasonic treatment in acetone, etched by $5 \%$ hydrofluoric acid, and rinsed in deionized water prior to loading into the CVD system. The growth pressure $\left(P_{G}\right)$ and wire temperature $\left(T_{W}\right)$ were varied from 0.5 to 4.5 Torr and from 1500 to $2000^{\circ} \mathrm{C}$, respectively. The $\mathrm{SiF}_{4}, \mathrm{CH}_{4}$, and $\mathrm{H}_{2}$ gas flow rates were varied from 3.5 to $5.0 \mathrm{sccm}, 1.0$ to $5.0 \mathrm{sccm}$, and 70 to $150 \mathrm{sccm}$, respectively. The substrate temperature $\left(T_{S}\right)$ was varied from 250 to $500^{\circ} \mathrm{C}$.

The structural properties and bonding configuration of the $\mathrm{SiC}$ films were characterized by X-ray diffractometry (XRD), Fourier transform infrared absorption spectroscopy (FTIR), and X-ray photoelectron spectroscopy (XPS).

\section{Results and Discussion}

Figures 1 and 2 show the dependence of FT-IR spectra and the concentration of elements in the film on the growth pressure, respectively. Low growth pressure resulted in a narrow full width at half maximum (FWHM) of the Si-C bond at $800 \mathrm{~cm}^{-1}$. The narrow FWHM suggested that crystalline SiC films were obtained. From the XPS measurements, $\mathrm{F}$ was found to be incorporated in the film and its concentration increased with increasing growth pressure. Therefore, at a higher growth pressure, the film might be amorphous $\mathrm{SiC}$. Because the mean free path is shorter at a higher pressure, the flux of atomic hydrogens generated on the wire might decrease in number on the growth surface by a gas-phase reaction. Thus, the extraction reaction of $\mathrm{F}$ on the growth surface by $\mathrm{H}^{*}$ may be suppressed with decreasing $\mathrm{H}^{*}$ concentration.

The temperature of the $\mathrm{W}$ wire was varied to increase the flux of precursors $\left(\mathrm{SiF}_{\mathrm{x}}^{*}\right.$ and $\left.\mathrm{CH}_{\mathrm{x}}^{*}\right)$ and $\mathrm{H}^{*}$ on the growth surface. Figures 3 and 4 show the dependence of deposition rate and FT-IR spectra on the wire temperature $T_{W}$, respectively. A higher wire temperature resulted in a higher deposition rate. Thus, the flux of the precursors seemed to increase with increasing wire temperature. However, the FWHM of the Si-C peak in the FT-IR spectra became wider at the higher wire temperature. This result suggests that the ratio of $\mathrm{SiF}_{\mathrm{x}}^{*}$ to $\mathrm{CH}_{\mathrm{x}}^{*}$ on the growth surface changes because of the difference of the gas decomposition temperature on the $\mathrm{W}$ wire between $\mathrm{SiF}_{4}$ and $\mathrm{CH}_{4}$. 
The SiC films were grown with various $\mathrm{CH}_{4} / \mathrm{SiF}_{4}$ flow rate ratios. Figures 5 and 6 show the dependence of the XRD pattern and the $\mathrm{SiC}$ grain size on the $\mathrm{CH}_{4} / \mathrm{SiF}_{4}$ ratio, respectively. From the XRD pattern, $\mu \mathrm{c}-3 \mathrm{C}-\mathrm{SiC}$ films were successfully obtained by controlling the $\mathrm{CH}_{4} / \mathrm{SiF}_{4}$ ratio. The $\mathrm{SiC}$ grain size was calculated by the Scherrer equation from the FWHM values of the $3 \mathrm{C}-\mathrm{SiC}$ peak. The grain size became maximum at a $\mathrm{CH}_{4} / \mathrm{SiF}_{4}$ ratio of around 0.6. Thus, it is suggested that the most suitable $\mathrm{CH}_{4} / \mathrm{SiF}_{4}$ flow rate ratio changes when the $\mathrm{W}$ wire temperature changes.

Figure 7 shows the dependence of the XRD pattern on the $\mathrm{CH}_{4} / \mathrm{SiF}_{4}$ ratio and the substrate temperature. At the $\mathrm{CH}_{4} / \mathrm{SiF}_{4}$ ratio of 1 , crystalline $\mathrm{SiC}$ could not be obtained at $300^{\circ} \mathrm{C}$. On the other hand, at the ratio of 0.4 , we succeeded in growing $\mu \mathrm{c}-\mathrm{SiC}$ films at the low substrate temperature of $250^{\circ} \mathrm{C}$. Generally, it is well known that the role of atomic hydrogens, such as in the hydrogen termination at the surface, is very important in the crystal growth of $\mathrm{Si}$ and $\mathrm{SiC}$ films at low substrate temperatures. ${ }^{13,14)}$ In this study, the effect of the $\mathrm{F}$ radicals is also important in $\mathrm{SiC}$ crystal growth. Therefore, it is considered that the flux ratio of precursors, atomic hydrogens, and F radicals are a key factor in determining film crystallinity. The results of this study are in agreement with this consideration.

In the $\mathrm{SiC}$ films grown in this study, the Si-H configuration was not detected in the FTIR spectra, although the substrate temperature decreased to $250^{\circ} \mathrm{C}$. Figure 8 shows the dependence of the FT-IR spectra on the substrate temperature. No peak at around 2000 to $2100 \mathrm{~cm}^{-1}$, originating from Si-H bonds, was detected. Generally, a-Si and $\mu \mathrm{c}-\mathrm{Si}$ films grown by HW-CVD contain comparatively little hydrogen, less than that of films grown by PECVD. ${ }^{15,16)}$ However, in this study, the $\mathrm{H}$ concentration in the film was almost $0 \%$. This result suggests that the $\mathrm{F}$ radicals generated from $\mathrm{SiF}_{4}$ prevent the incorporation of $\mathrm{H}$ in the film. Therefore, controlling the concentration ratio of atomic hydrogens and $\mathrm{F}$ radicals on the growth surface is also important for improving crystallinity.

\section{Conclusions}

$\mathrm{SiC}$ films were grown by $\mathrm{HW}-\mathrm{CVD}$ using a $\mathrm{SiF}_{4} / \mathrm{CH}_{4} / \mathrm{H}_{2}$ mixture at a low substrate temperature, and their structural properties were characterized. Microcrystalline 3C- 
$\mathrm{SiC}(111)$ films were successfully obtained at $250^{\circ} \mathrm{C}$. The film crystallinity is improved by controlling the growth pressure and the $\mathrm{CH}_{4} / \mathrm{SiF}_{4}$ flow rate ratio. No Si-H bonds were detected, although the substrate temperature decreased to $250^{\circ} \mathrm{C}$. The results suggest the importance of the ratio of atomic hydrogens to $\mathrm{F}$ radicals on the growth surface. 


\section{References}

1) H. Matsunami and T. Kimoto: Mater. Sci. Eng. R 20 (1997) 125.

2) K. Yasui, J. Eto, Y. Narita, M. Takata, and T. Akahane: Jpn. J. Appl. Phys. 44 (2005) 1361.

3) D. Kuhman, S. Grammatica, and F. Jansen: Thin Solid Films 177 (1989) 253.

4) D. S. Kim and Y. H. Lee: Thin Solid Films 283 (1996) 109.

5) G. Cicala, P. Capezzuto, G. Bruno, and M. C. Rossi: Appl. Surf. Sci. 184 (2001) 66.

6) A. Kumbhar, S. B. Patil, S. Kumar, R. Lal, and R. O. Dusane: Thin Solid Films 395 (2001) 244.

7) S. Miyajima, A. Yamada, and M. Konagai: Jpn. J. Appl. Phys. 43 (2004) L1190.

8) G. Ganguly, S. C. De, S. Ray, and A. K. Barua: J. Appl. Phys. 69 (1991) 3915.

9) G. Ganguly, J. Dutta, S. Ray, and A. K. Barua: Phys. Rev. B 40 (1989) 3830.

10) T. Takeshita, K. Ichige, Y. Kurata, and S. Hasegawa: J. Appl. Phys. 69 (1991) 7945.

11) A. H. Mahan, D. L. Williamson, M. Ruth, and P. Raboisson: J. Non-Cryst. Solids $77.78(1985) 861$.

12) C. Wang, G. Lucovsky, and R. J. Nemanich: J. Non-Cryst. Solids 137-138 (1991) 741.

13) K. Abe, T. Watahiki, A. Yamada, and M. Konagai: Jpn. J. Appl. Phys. 37 (1998) 1202.

14) B. P. Swain, T. K. G. Rao, M. Ro, J. Gupta, and R. O. Dusane: Thin Solid Films 501 (2006) 173.

15) A. H. Mahan, J. Carapella, B. P. Nelen, R. S. Crandall, and I. Balberg: J. Appl. Phys. 69 (1991) 6728.

16) A. Masuda, C. Niikura, Y. Ishibashi, and H. Matsumura: Sol. Energy Mater. Sol. Cells 66 (2001) 259. 


\section{Figure captions}

Fig. 1. FT-IR spectra as a function of the growth pressure. The films were grown at $T_{W}$ of $1800^{\circ} \mathrm{C}, T_{S}$ of $500^{\circ} \mathrm{C}$, and $\mathrm{CH}_{4} / \mathrm{SiF}_{4}$ flow rate ratio $(R)$ of 1.0 .

Fig. 2. Dependence of film composition obtained from XPS on the growth pressure. The films were grown at $T_{W}$ of $1800^{\circ} \mathrm{C}, T_{S}$ of $500^{\circ} \mathrm{C}$, and $R$ of 1.0 .

Fig. 3. Dependence of deposition rate on the $\mathrm{W}$ wire temperature. The films were grown at $T_{S}$ of $500^{\circ} \mathrm{C}, R$ of 1.0 , and $P_{G}$ of 1.0 Torr.

Fig. 4. FT-IR spectra as a function of the $\mathrm{W}$ wire temperature. The films were grown at $T_{S}$ of $500^{\circ} \mathrm{C}, R$ of 1.0 , and $P_{G}$ of 1.0 Torr.

Fig. 5. XRD pattern as a function of the ratio of $\mathrm{CH}_{4} / \mathrm{SiH}_{4}$ flow rate. The films were grown at $T_{W}$ of $2000^{\circ} \mathrm{C}, T_{S}$ of $500^{\circ} \mathrm{C}$, and $P_{G}$ of 1.0 Torr.

Fig. 6. Dependence of $\mathrm{SiC}$ grain size on the $\mathrm{CH}_{4} / \mathrm{SiH}_{4}$ ratio. The films were grown at $T_{W}$ of $2000^{\circ} \mathrm{C}, T_{S}$ of $500^{\circ} \mathrm{C}$, and $P_{G}$ of 1.0 Torr.

Fig. 7. XRD pattern as a function of the substrate temperature and the $\mathrm{CH}_{4} / \mathrm{SiF}_{4}$ ratio at $T_{W}$ of $2000^{\circ} \mathrm{C}$ and $P_{G}$ of 1.0 Torr. (a) $\mathrm{CH}_{4} / \mathrm{SiF}_{4}$ ratio is 1.0 . (b) $\mathrm{CH}_{4} / \mathrm{SiF}_{4}$ ratio is 0.4 .

Fig. 8. FT-IR spectra as a function of the substrate temperature. The films were grown at $T_{W}$ of $2000^{\circ} \mathrm{C}, R$ of 1.0 , and $P_{G}$ of 1.0 Torr. 
Fig. 1

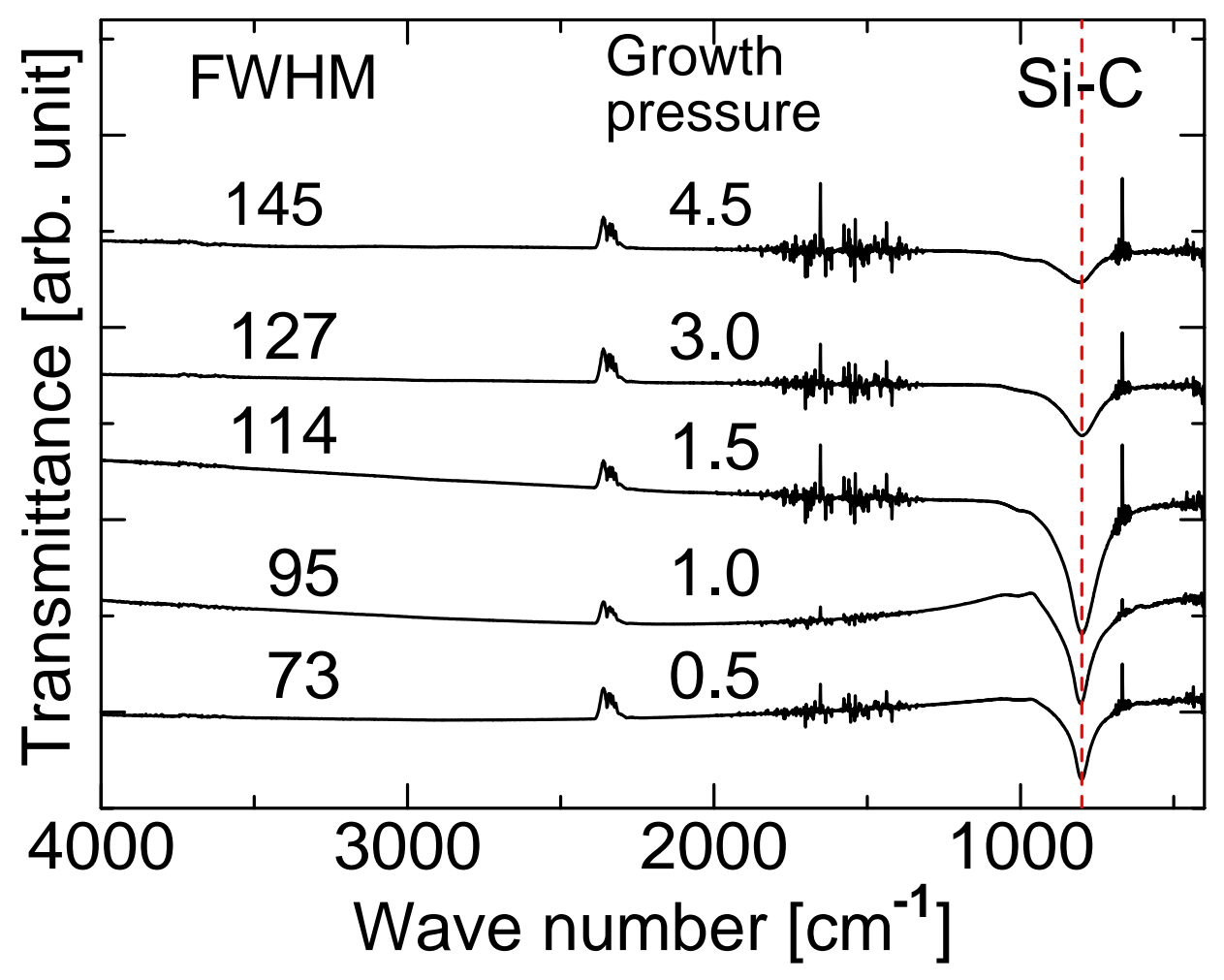


Fig. 2

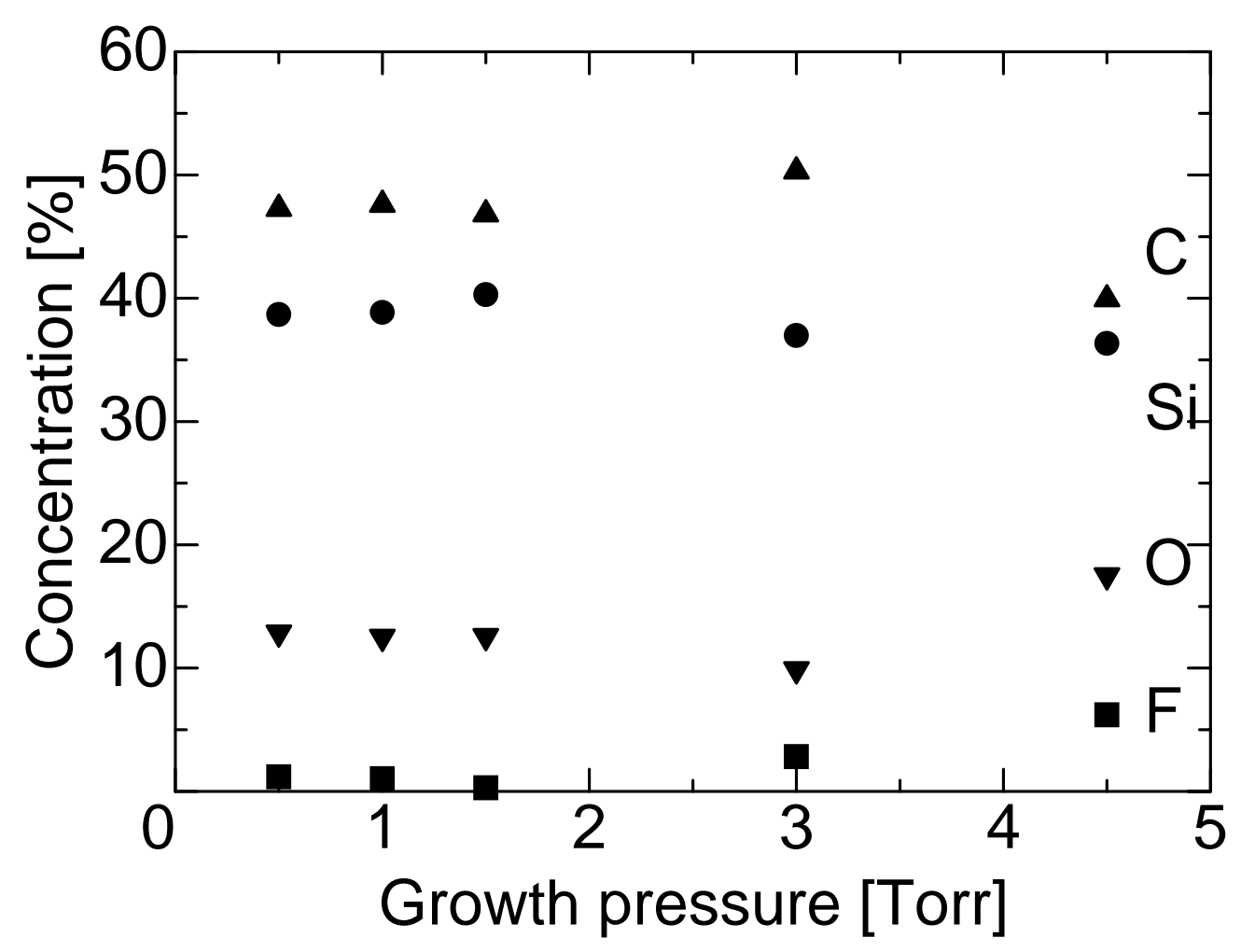


Fig. 3

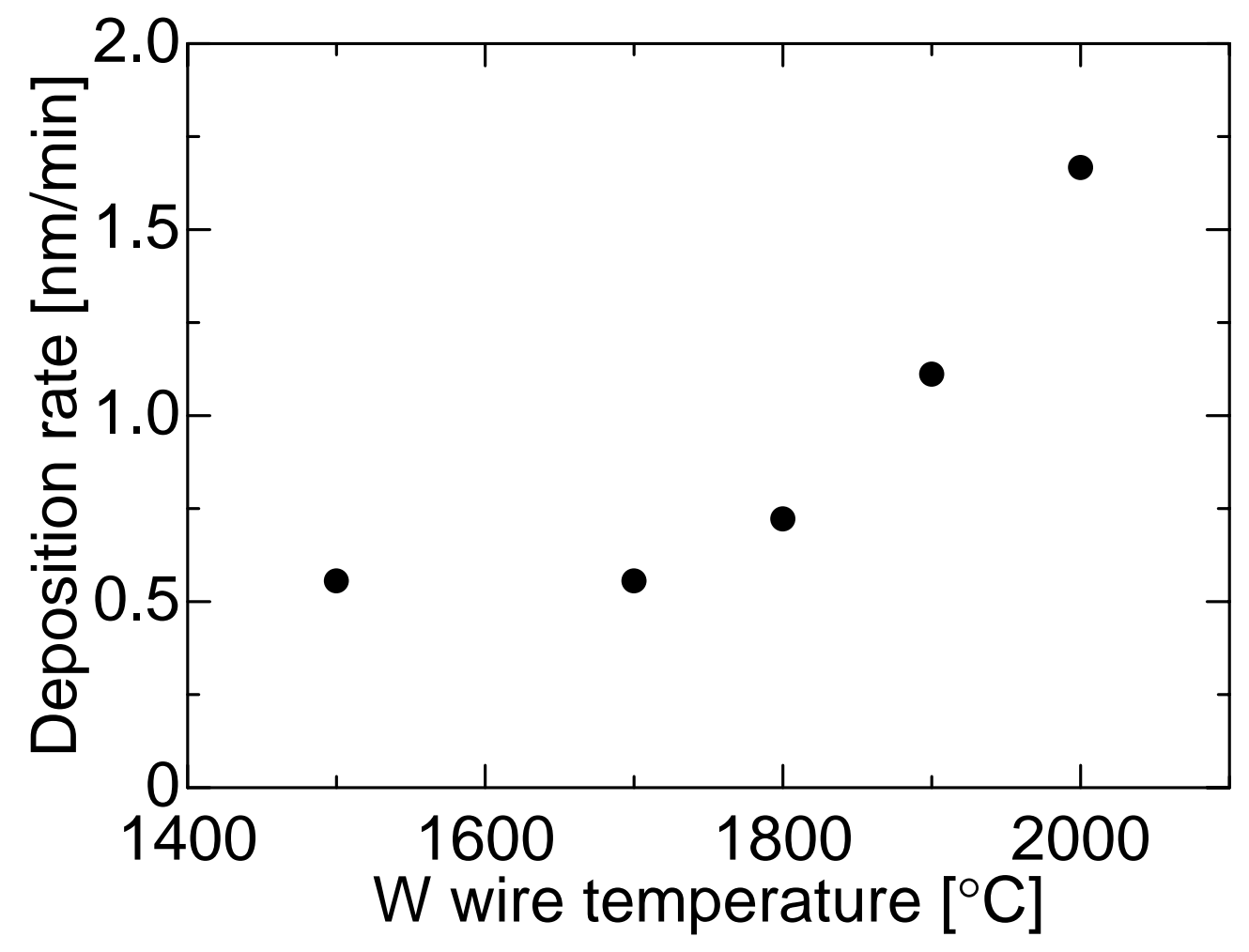


Fig. 4

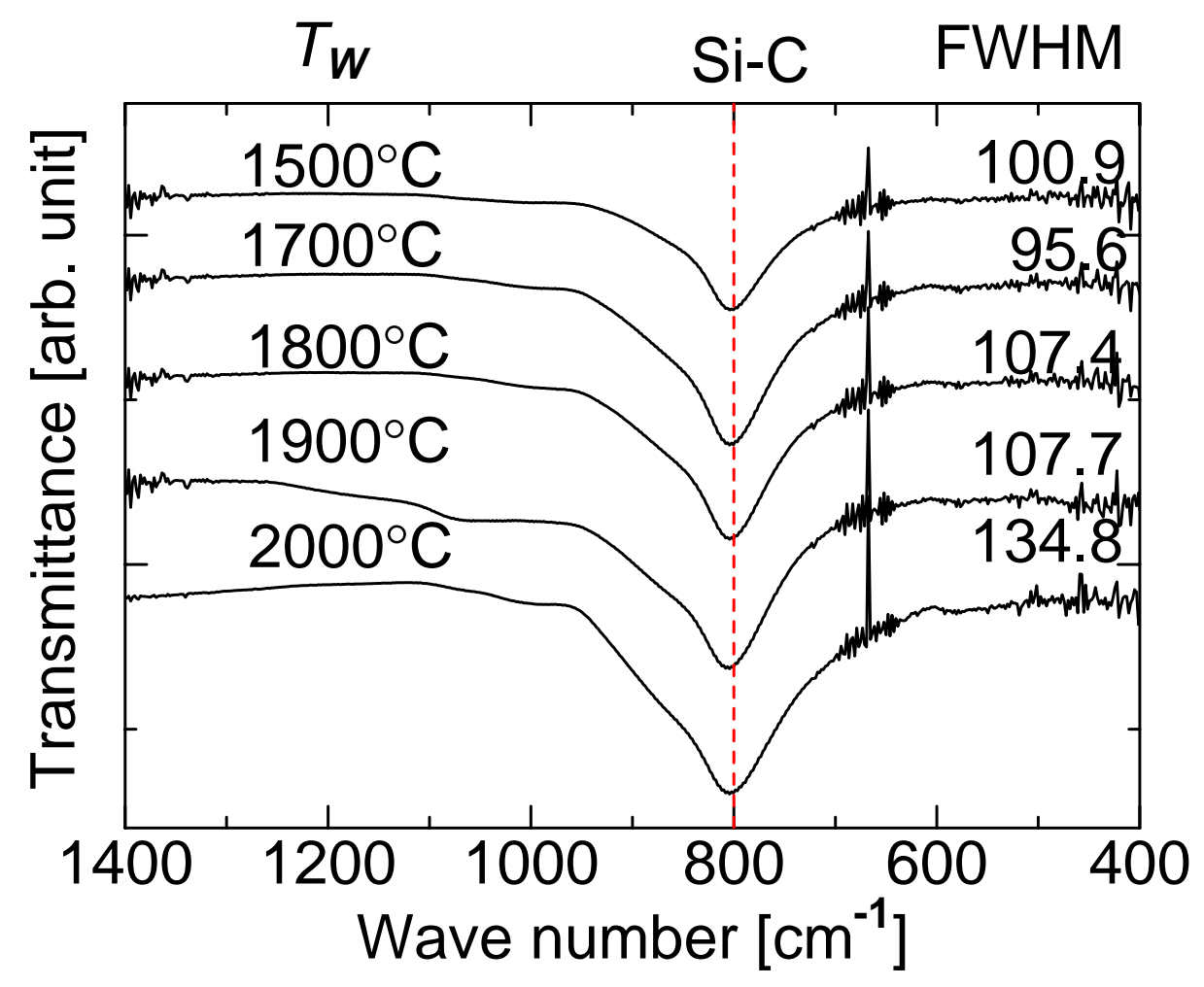


Fig. 5

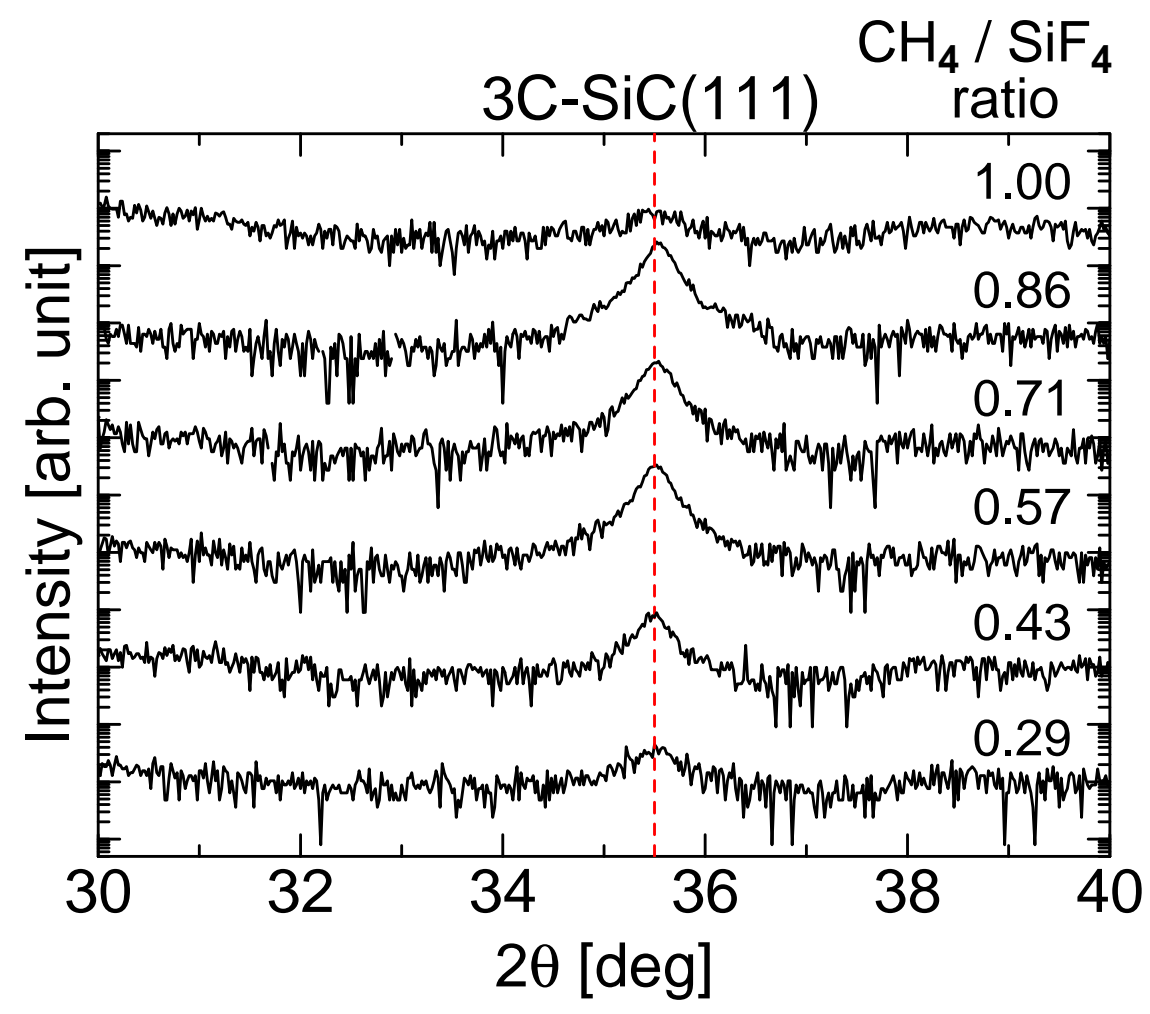


Fig. 6

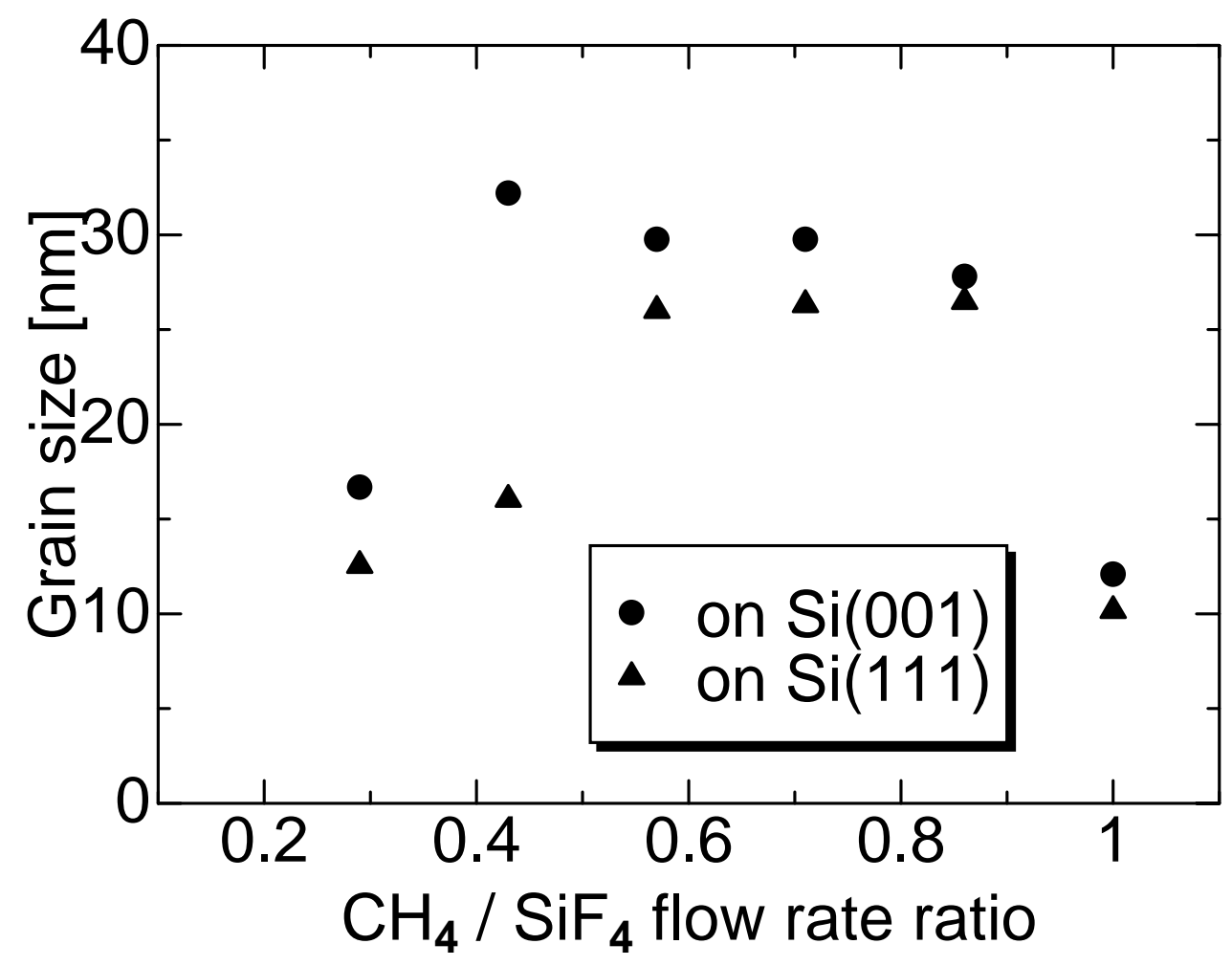




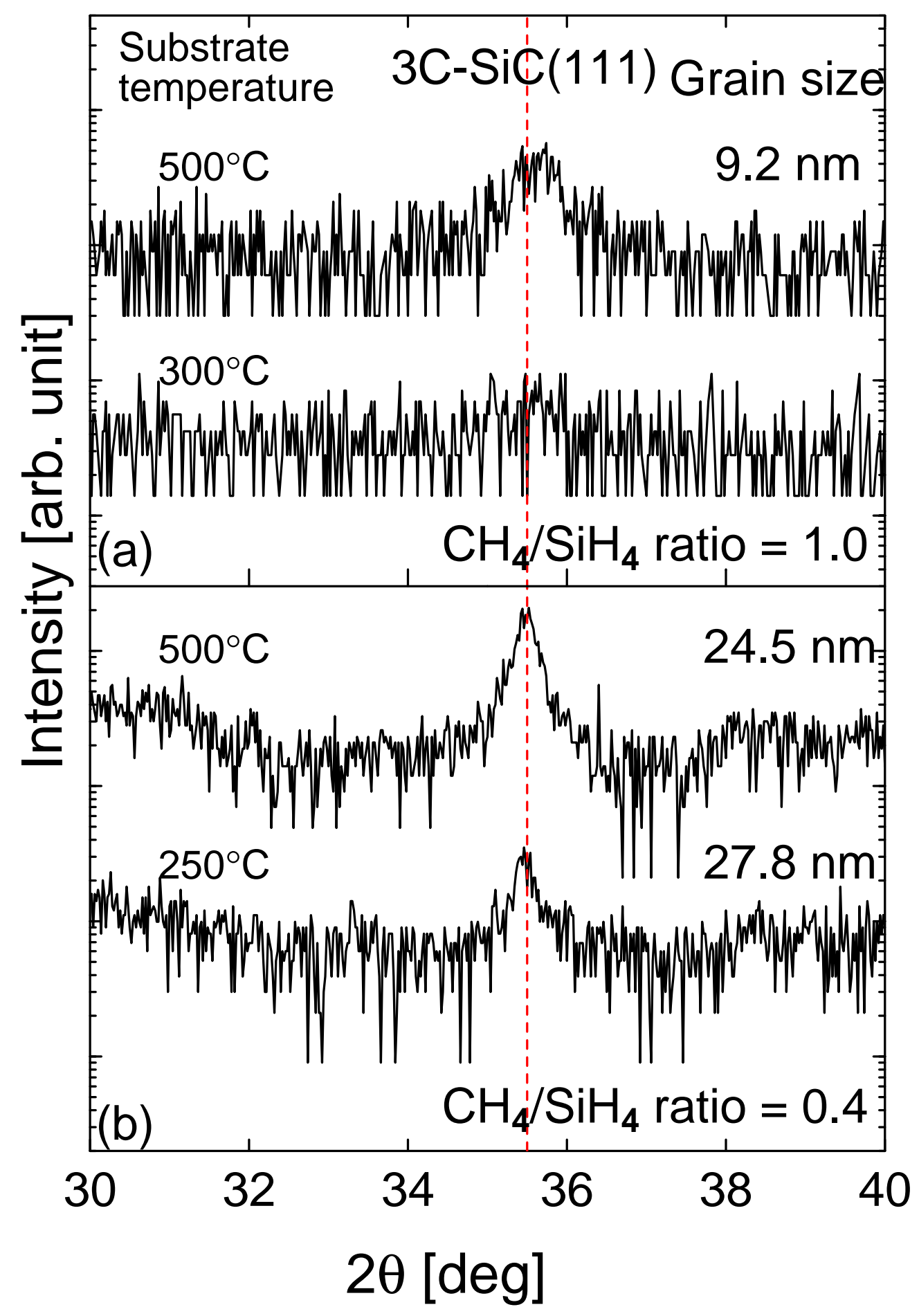


Fig. 8

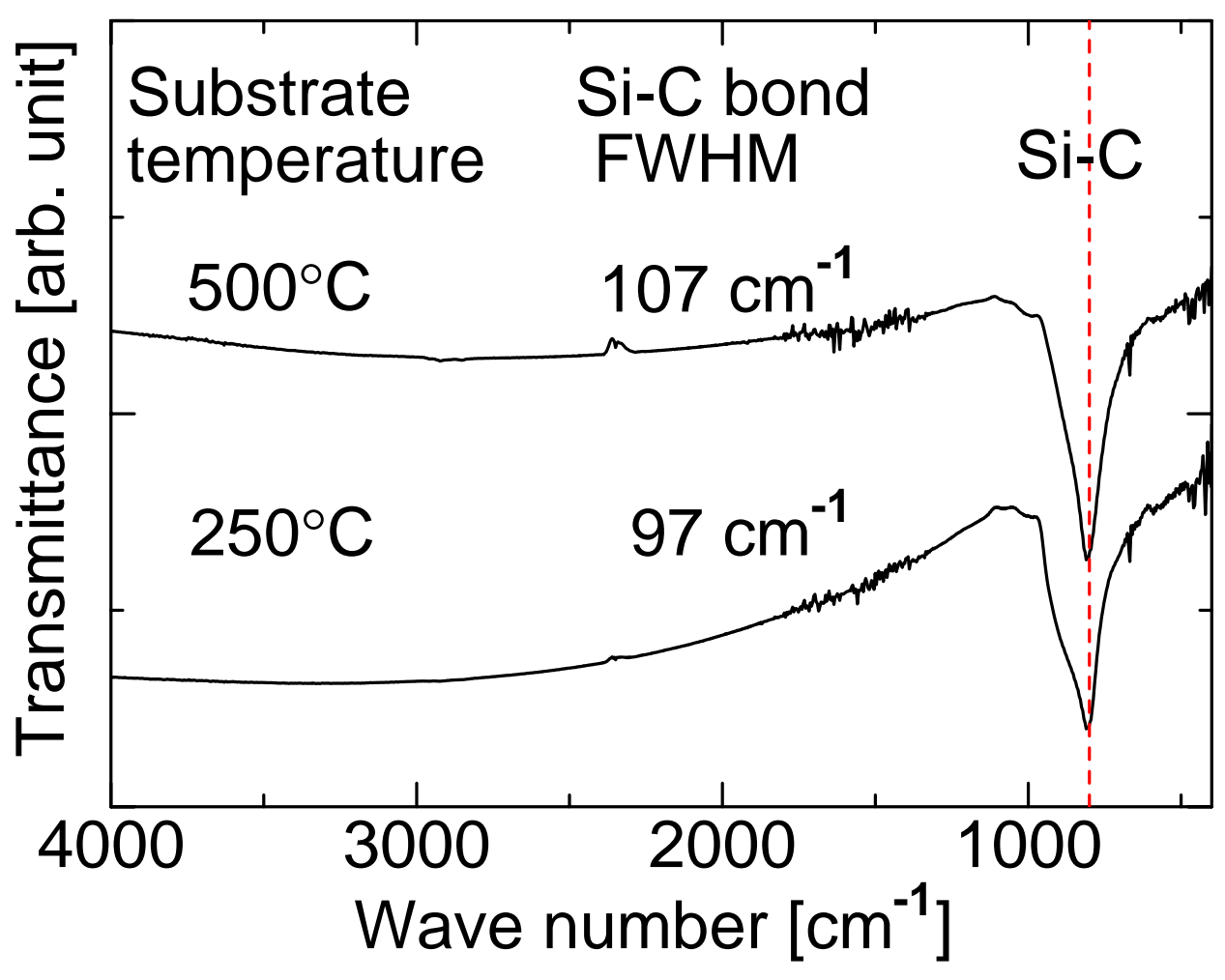

